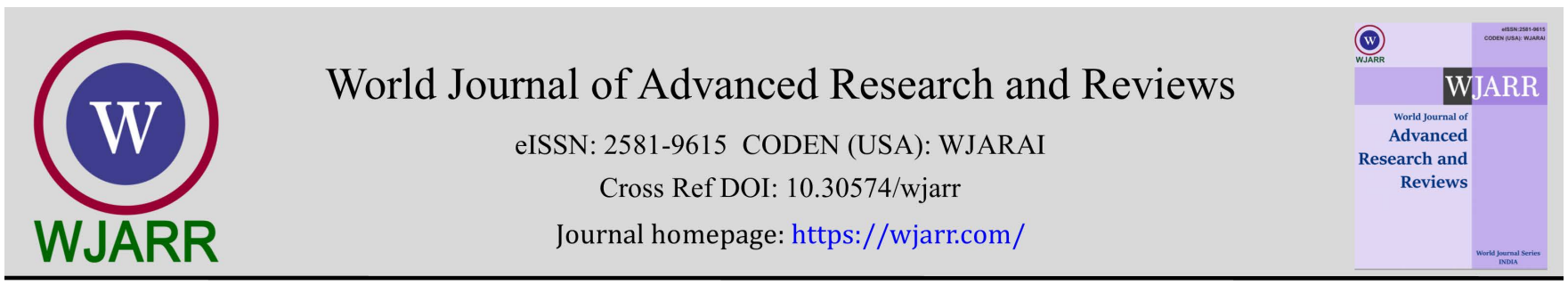

(RESEARCH ARTiClE)

Check for updates

\title{
Immunohistochemical characterization of KS cases seen in Nnewi Anambra state using HHV-8 LNA1 and HIV-1P24 antibodies
}

Felix Emeka Menkiti 1, ${ }^{*}$, Cornelius Ozobia Ukah 1, Ifeoma Oluchukwu Menkiti 2, Ifeoma Florence Ezejiofor 1 and Kayode A Adelusola ${ }^{3}$

${ }^{1}$ Department of Anatomic Pathology and Forensic Medicine, Nnamdi Azikiwe University, Nnewi Campus, Anambra state, Nigeria.

${ }^{2}$ School of Nursing, Nnamdi Azikiwe University Teaching Hospital, Nnewi.

3 Department of Morbid Anatomy and Forensic Medicine, Obafemi Awolowo University Teaching Hospital Complexes (OAUTHC), Ile-Ife, Osun State, Nigeria.

World Journal of Advanced Research and Reviews, 2021, 11(03), 120-126

Publication history: Received on 06 August 2021; revised on 10 September 2021; accepted on 12 September 2021

Article DOI: https://doi.org/10.30574/wjarr.2021.11.3.0436

\begin{abstract}
Introduction: Kaposi sarcoma (KS) is of public health significance in sub-Saharan Africa, including Nigeria, especially in the era of HIV/AIDS. Several works have been done on the prevalence and patterns of KS both in Nigeria and other parts of Africa, with a reported significant prevalence. We employed immunohistochemistry to characterise the morphologic KS cases seen in Nnewi.
\end{abstract}

Materials and Methods: The Formalin Fixed, Paraffin Embedded (FFPE) tissue blocks of all haematoxylin and eosin (H\&E) diagnosed cases of KS seen in the archives of histopathology facilities in Nnewi, Anambra State over 15 year period were retrieved. Fresh sections were made from the tissue blocks of the 82 cases that met the inclusion criteria for the study, and were subjected to immunohistochemistry using HHV-8 LNA1 (Human Herpes Virus-8 Latent nuclear antigen1) and HIV-1p24 antibodies and reviewed.

Results: A total of 82 KS cases were studied, 69 of which were confirmed KS cases on immunohistochemistry. KS accounted for $1.20 \%$ and $14.47 \%$ of solid malignancies and sarcomas respectively. Nearly $80 \%$ of these were HIV/AIDSassociated, 59.3\% of which occurred in females. KS occurred more in the third decade with an age range of 7-74years.

Conclusion: KS is quite common in our environment and is largely HIV/AIDS associated. Reducing the burden of HIV/AIDS will invariably reduce KS burden.

Keywords: Analysis; HHV8 LNA-1; HIV-1p24; Immunohistochemistry; Kaposi Sarcoma

\section{Introduction}

KS is a tumour of uncertain histogenesis caused by Human Herpes virus-8 (HHV-8), but is widely regarded to be of vascular endothelial origin [1]. It is the most frequent HIV-associated malignancy worldwide and remains a major scourge in sub-Saharan Africa [2]. KS is also endemic in most of Africa, being now the most frequently reported cancer in some areas of Africa [2]. Until the advent of organ transplantation and HIV/AIDS, KS as described Moritz Kaposi was relatively rare [3].

\footnotetext{
${ }^{*}$ Corresponding author: Felix Emeka Menkiti

Department of Anatomic Pathology and Forensic Medicine, Nnamdi Azikiwe University, Nnewi Campus, Anambra state, Nigeria.

Copyright $(2021$ Author(s) retain the copyright of this article. This article is published under the terms of the Creative Commons Attribution Liscense 4.0.
} 
HIV-associated KS is a public health challenge in sub-Saharan Africa since both the causative agent HHV-8, also called Kaposi sarcoma associated-herpesvirus (KSHV) and the major risk factor, HIV, are prevalent and closely associated [2]. Due to this close association, most reports on KS has been in the setting of HIV/AIDS, though literatures had documented KS long before the first documentation in the setting of HIV/AIDS [4]. This is the most aggressive clinico-epidemiologic form, being particularly commoner in homosexuals and bisexual men infected with Human Immunodeficiency Virus-1 (HIV-1) [5]. KS in this setting is an AIDS-defining illness, and the burden has been reduced world-wide with the advent of highly active antiretroviral therapy (HAART) [5]. It often involves lymph nodes, disseminates widely to viscera early in its course and most patients eventually die of opportunistic infections rather than KS [6].

The other clinico-epidemiologic forms are: the classic (European) KS observed chiefly among elderly people in the Mediterranean region, eastern Europe, and the Middle East; ${ }^{7}$ the iatrogenic (immunosuppression related) KS occurring few months to years after the onset of immunosuppressive therapy; and the endemic (African) KS that occurs in younger age group with male predominance [1,7]. KS most typically, but not exclusively involves the skin [5].

Diagnosis of KS requires morphologic evaluation and demonstration of HHV-8 LNA1 immunohistochemical staining [8, 9]. Although the morphologic picture is characteristic, immunohistochemistry remains indispensible for the exclusion of the several morphologic mimickers $[9,10]$. Studies have also shown that the presence of HIV infection can be detected in archived histopathology specimen using HIV-1p24 immunohistochemical stain [11, 12]. This can therefore be exploited in classifying KS into two tiers: HIV/AIDS associated and non-HIV/AIDS associated.

This study is aimed at characterising all KS lesions diagnosed in Nnewi, Anambra State immunohistochemically using HHV-8 LNA1 monoclonal antibody and monoclonal antibody to HIV-1p24 antigen, to confirm diagnosis as well as classify the KS lesions.

\section{Material and methods}

This is a retrospective study on the Formalin fixed and Paraffin Embedded (FFPE) tissue blocks of all histologically diagnosed (using H\&E only) KS cases in the archives of the histopathology laboratories in Nnewi, Anambra State over a 15-year period (January 2006 and December 2020). The two specialist histopathology laboratories providing services to Nnewi and its environ, and which were used for this study include the Histopathology Department of Nnamdi Azikiwe University Teaching Hospital, Nnewi (a federal teaching hospital) and Pathocon Specialist Clinic and Research Institute, Nnewi, (a well-staffed private Pathology laboratory/ diagnostic centre established in 2007 by two Pathologists). The cases with missing tissue blocks, poorly preserved tissue blocks and tissue blocks with inadequate tissue left for sectioning were excluded.

\subsection{Laboratory procedure}

The FFPE tissue blocks were retrieved and fresh sections were made. These were stained using H\&E histochemical stains and immunostained for HHV-8 LNA1 and HIV-1p24 using the indirect immunoperoxidase method. The tissue sections were deparaffinised using xylene and then rehydrated in decreasing alcohol concentrations. The antigens retrieval was by heat induced epitope retrieval (HIER) method. Three percent hydrogen peroxide was used to inhibit endogenous peroxidase activity, and the tissues incubated with the primary antibodies, rinsed and then followed by the use of secondary detection system, using diaminobenzene (DAB) as chromogen. Immuno-staining was performed using HHV-8 (monoclonal antibody to latent nuclear antigen [LNA-1], dilution 1:200, 30-minute incubation); and HIV-1p24 (HIV particle capsid, dilution 1:10, 30 minutes incubation) with control in parallel. All steps were carried out at room temperature.

\subsection{Interpretation of result}

HHV-8 LNA1 was considered 'positive' when the staining was observed exclusively in the tumour cell nuclei (including spindle cells and endothelial cells), has a granular or diffuse appearance, and has no concomitant cytoplasmic staining. The HIV-1p24 immunostain was interpreted as 'positive' when there is distinct 'cytoplasmic or peri-cytoplasmic' staining of $>10 \%$ of the lesional cells. A known HIV positive tissue that stained positive for p24 and HHV-8 positive tissues were used as control.

\subsection{Data Analysis}

The data analysis was done using the IBM, Chicago Statistical Package for Social Sciences (SPSS) software version 20.0 and the result presented with tables and charts. 


\section{Results}

A total of twenty five thousand, three hundred and ninety-one $(25,391)$ surgical specimens were received in both facilities in the years under review. Of these, five thousand, seven hundred and sixty-five (5765) were solid malignancies, including five thousand, two hundred and eighty-eight (5288) carcinomas and four hundred and seventyseven (477) sarcomas. Ninety six (96) cases were diagnosed as KS on light microscopy, eighty-two (82) of which met the inclusion criteria and were used in this study.

Of the 82 morphologically diagnosed cases of KS analysed, 69 were immunoreactive to HHV-8 LNA1 antibody (Figure $1 a-b)$, accounting for $84.15 \%$. Among the HHV-8 LNA1 positive cases, 54 (78.3\%) were positive to HIV-1p24 immunostaining (Table 1 and figure 1c). KS therefore accounted for $1.20 \%$ and $14.47 \%$ of solid malignancies and sarcomas respectively.

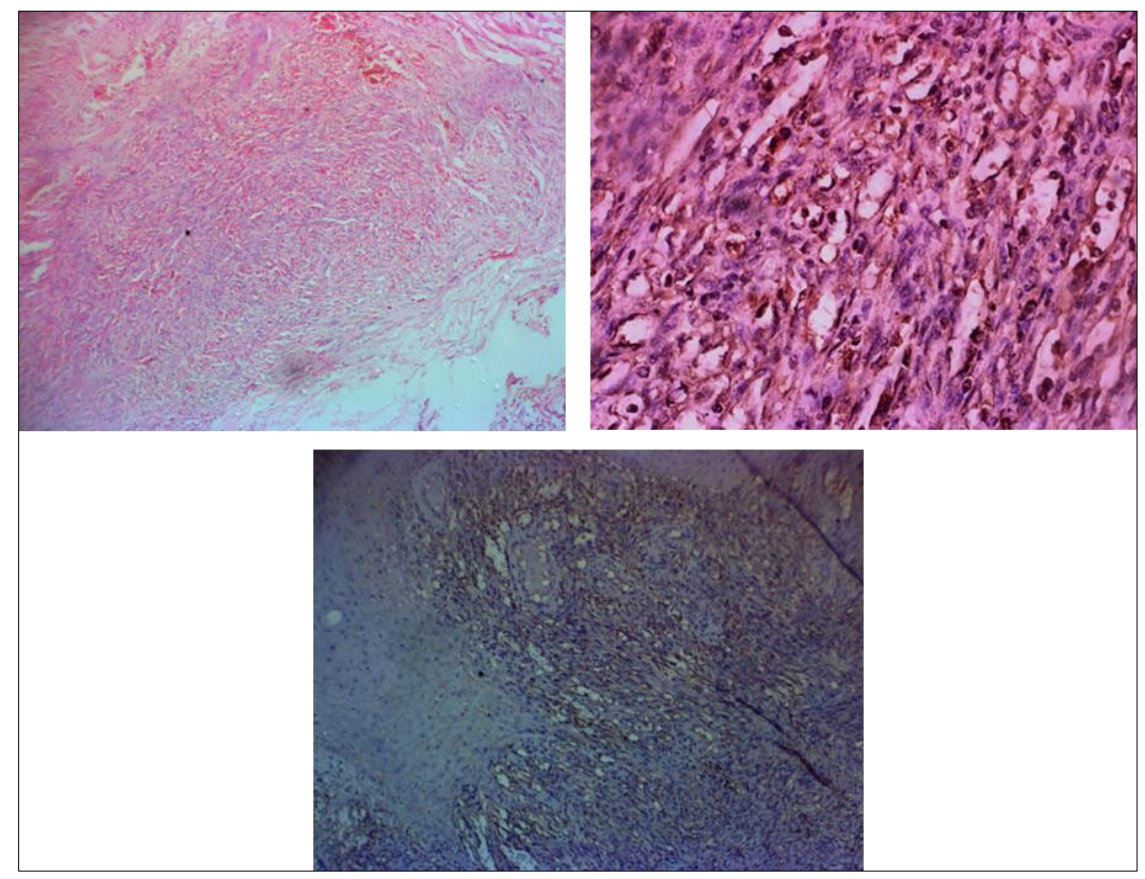

Figure 1 Nodular stage KS showing intersecting fascicles of spindle cells with numerous slit-like spaces containing red cells and some stromal inflammatory cells (A=H\&E X1000) with nuclear immunohistochemical staining to HHV8 LNA1 antibody (B=X200) and cytoplasmic immunohistochemical staining to HIV-1p24 (C=X100)

Table 1 Age distribution of KS

\begin{tabular}{|c|c|c|c|l|}
\hline \multicolumn{2}{|c|}{} & HIV/AIDS associated & Non-HIV/AIDS associated & Total \\
\hline \multirow{4}{*}{ Age range } & $1-10$ & 2 & 1 & 3 \\
\cline { 2 - 5 } & $11-20$ & 2 & 2 & 4 \\
\cline { 2 - 5 } & $21-30$ & 18 & 1 & 19 \\
\cline { 2 - 5 } & $31-40$ & 12 & 1 & 13 \\
\cline { 2 - 5 } & $41-50$ & 11 & 3 & 14 \\
\cline { 2 - 5 } & $51-60$ & 6 & 2 & 3 \\
\cline { 2 - 6 } & $61-70$ & 3 & 2 & 3 \\
\cline { 2 - 6 } & $71-80$ & 0 & 3 & 69 \\
\hline \multicolumn{2}{|c|}{ Total } & 54 & 15 & \\
\hline
\end{tabular}


The age range for KS was from 4 to 73 years, with a peak incidence in the third decade. There were 3 cases noted to occur in the first decade of life: 2 were HIV/AIDS associated whereas 1 was related to immunosuppression in a child being managed for non-Hodgkin lymphoma. The mean age of occurrence was $38.8 \pm 16.3$ years.

Of the 69 cases studied, 34 were males while 35 were females with a male: female ratio of 1:1.1. However, there is female preponderance (32/54) for the HIV/AIDS associated KS. (Table 2)

Table 2 Sex distribution of KS

\begin{tabular}{|l|l|c|c|c|}
\hline \multicolumn{2}{|c|}{ Patient's sex } & HIV/AIDS associated & Non-HIV/AIDS Associated & Total \\
\hline \multirow{2}{*}{} & Male & 22 & 12 & 34 \\
\cline { 2 - 5 } & Female & 32 & 3 & 35 \\
\hline \multicolumn{2}{|l}{ Total } & 54 & 15 & 69 \\
\hline
\end{tabular}

Figure 3 shows the site distribution of KS, with most KS occuring in the lower limb, followed by the head and neck region. 2 cases were generalised while 5 were intraabdominal (figure2)

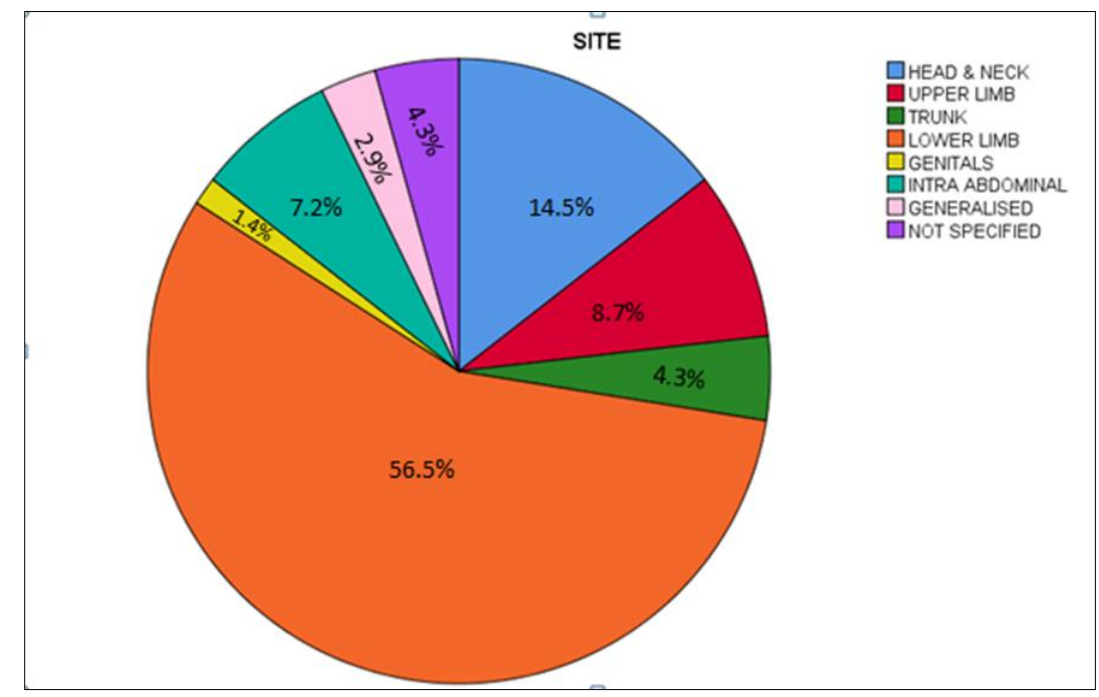

Figure 2 Chart displaying the distribution of KS by site

Majority (69.6\%) were diagnosed at morphologic nodular stage of the lesion (Table 3)

Table 3 Morphologic stage of KS at diagnosis

\begin{tabular}{|l|l|c|c|}
\hline \multicolumn{2}{|c|}{ Stage } & Frequency & Percent \\
\cline { 2 - 4 } & Patch & 2 & 2.9 \\
\cline { 2 - 4 } & Plaque & 19 & 27.5 \\
\cline { 2 - 4 } & Nodular & 48 & 69.6 \\
\cline { 2 - 4 } & Total & 69 & 100.0 \\
\hline
\end{tabular}

\section{Discussions}

Kaposi sarcoma is a relatively rare cancer, estimated by GLOBOCAN to account for $0.2 \%$ of all new cancer cases and cancer deaths worldwide [13]. The statistics is still significant in some African countries, including Nigeria where it accounts for $0.94 \%$ and $0.87 \%$ of new cancer cases and cancer deaths respectively [14]. In this study, KS accounted for $1.20 \%$ and $14.47 \%$ of solid malignancies and sarcomas respectively. This is in agreement with a previous study done in 
South-east Nigeria [9], but lower than most African studies which did not apply immunohistochemistry in their analysis, Nigeria inclusive [15-18]. Diagnostic errors could be as high as 20\% when KS diagnosis is based only on morphology [9]. HHV-8 LNA1 excludes KS mimics, being specific for Kaposi Sarcoma Herpes virus associated lesions [9, 19]. Also, the difference in frequency between this study and those referenced may be attributed to the geographic variation in the incidences of KS (see figure 3) [13]

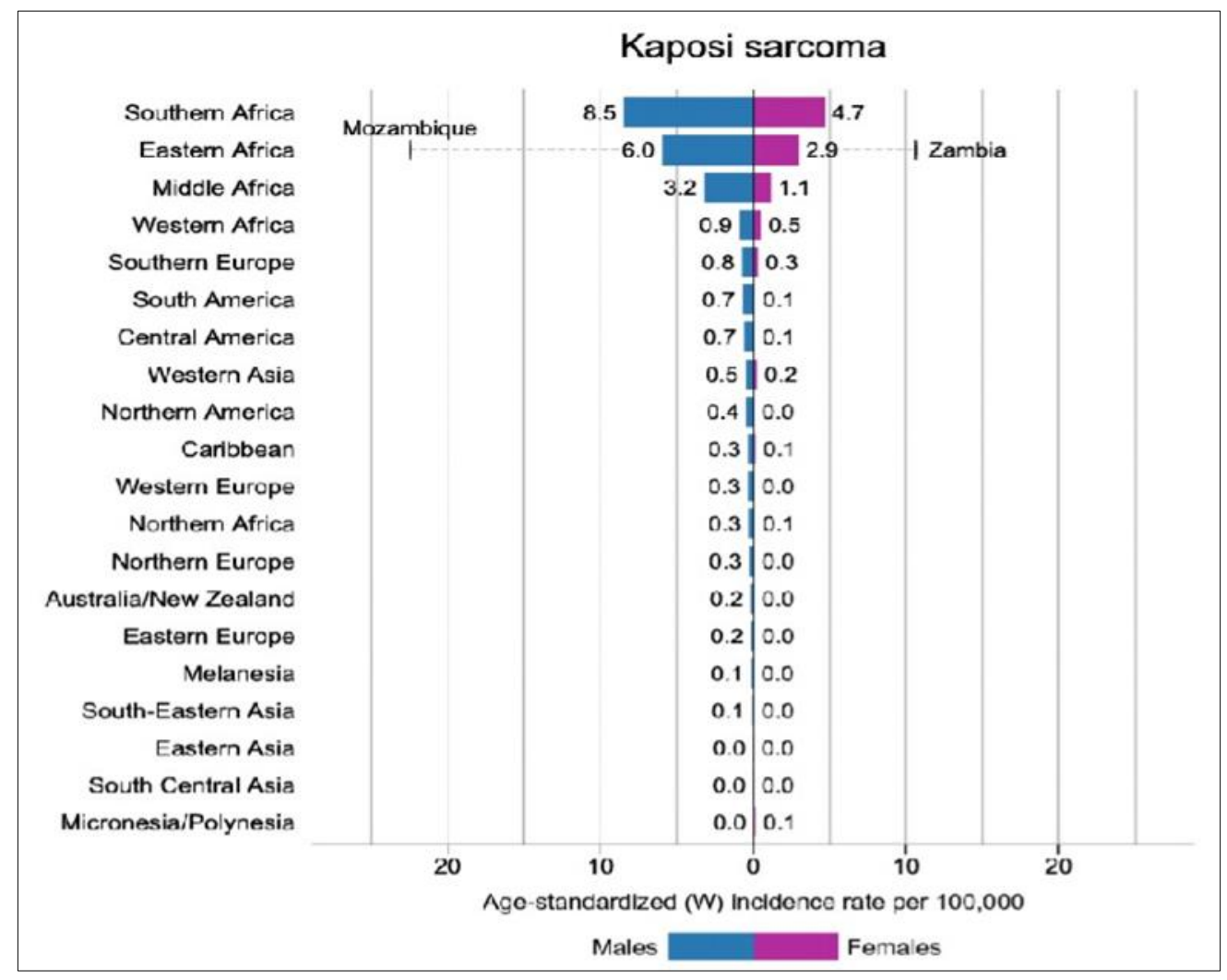

Figure 3 Adapted from Sung H, et al. Global Cancer Statistics 2020. 13

KS has been classified into four clinico-epidemiological forms including the Classic, Endemic (African), Iatrogenic and HIV/AIDS-associated KS [5]. In this study, majority (78.3\%) of the cases were HIV/AIDS-associated. Although this figure is high, it agrees with the works done in Lagos, Jos and Sokoto, Nigeria, in which HIV/AIDS-associated KS accounted for $88.5 \%, 59.4 \%$ and $59.3 \%$ respectively of KS cases [18, 20,21]. Although a Tanzanian work reported a lower rate $(49.2 \%)$ of HIV/AIDS-associated KS, it was still the commonest in that study [16]. These underscore the high burden as well as synergy of KS and HIV infection in Africa, where limited access to HAART and other preventive measures could be contributory [22], contrary to the experience in western countries where the incidence of HIV/AIDS-associated KS has dropped from about $15 \%$ to $0.3 \%$ [23].

We observed that KS showed fairly equal frequency for male (34) and female (35). However, HIV/AIDS-associated KS was noted to display a female preponderance (59.26\%), which is in agreement with previous studies done in Nigeria and Tanzania in Africa $[16,18]$. The female preponderance to HIV infection could account for this [24].

KS occurred over a wide age range of 4-73 years, similar to what has been reported in several literatures around the world $[16,21]$. The mean age for KS occurrence was $38.75 \pm 16.31$ years with a peak in the third decade (21-30years) of life. The peak age is in agreement with that recorded by the study in Kano and Zaria [25,26]. However, works done in Tanzania and Lagos reported peaks in the fourth and fifth decades respectively $[16,18]$. This reflects regional differences in the distribution of KS, corresponding with HIV modal age groups in the different regions: third decade for South east and North-west Nigeria where Anambra, Kano and Zaria belongs, and fifth decade for South west Nigeria where Lagos belongs [27]. HIV/AIDS infection therefore impacts greatly on the occurrence of KS, determining not only the disease burden but also the age of occurrence.

The KS lesions were observed to involve the lower limbs more than any other part of the body. Congruent with our previous study and that done in most part of Africa and China, most cases were diagnosed at morphologic nodular stage. 
This could be related to the fact that most KS occurred at the background of HIV/AIDS, which case is more aggressive. HIV/AIDS burden in china has been on the rise despite her healthcare reforms due to lack of emphasis on sexual education [28]. Also, there were reported high HIV prevalence (1.9\%) in South east Nigeria [24]. In addition, this late presentation could be attributed to ignorance, poverty, and limited access to health-care in Nigeria.

\section{Conclusion}

The burden of KS is still significant in our environment despite global decline, with 80\% HIV/AIDS association. A wellarticulated government policy and programme for HIV/AIDS prevention and management, with improved, costeffective universal health coverage for the citizens, especially the rural population will go a long way in reducing the overall burden of KS.

\section{Compliance with ethical standards}

\section{Disclosure of conflict of interest}

The authors Felix Emeka Menkiti, Cornelius Ozobia Ukah, Ifeoma Oluchukwu Menkiti, Ifeoma Florence Ezejiofor and Kayode A Adelusola declare that there are no conflicting interests in this study.

\section{Statement of ethical approval}

No human or animal subject was used in this study. However, approval was gotten from the ethics committee of Nnamdi Azikiwe University Teaching Hospital, Nnewi, Anambra State, Nigeria.

\section{References}

[1] Chor PJ, Santa Cruz DJ. Kaposi's sarcoma: a clinicopathologic review and differential diagnosis. J Cutan Pathol. 1992; 19: 6-20.

[2] Yuan C, John Z, Henry W, Edward K, Chris B, Thomas S, et al. Kaposi's Sarcoma-Associated Herpes virus and Kaposi's Sarcoma in Africa. Arch Intern Med. 1996; 156(2): 202-204.

[3] Hunt SJ, Santa cruz DJ, Barnhill R. Vascular tumors. In: Barnhill LR, Crowson AN, editors. Textbook of Dermatopathology. 2nd ed. New York: Mc-Graw-Hill. 2004; 821-870.

[4] Friedman-Kien A, Laubenstein L, Marmor M. Kaposi's sarcoma and pneumocystic pneumonia among homosexual men: New York and California. Morbidity and Mortality Weekly Report. 1981; 30: 305-308.

[5] Mentzel T, Knuutila S, Lamovec S. Kaposi Sarcoma. In: Fletcher DM, Julia AB, Hogendoorn PCW, Mertens F, editors. WHO classification of tumours of soft tissue and bone. 4th ed. Lyon: IARC press. 2012; 151-153.

[6] Mitchell RN. Blood vessels: Intermediate Grade Tumors. In: Kumar V, Abbas AK and Aster JC, editors. Robbins and Cotran Pathologic Basis of Disease. 9th ed. Philadelphia: Elsevier Saunders. 2015; 518-519.

[7] Iscovitch J, Boffeta P, Franceschi S. Classic Kaposi sarcoma, epidemiology and risk factors. Cancer. 2000; 88: 500517.

[8] Rosai J. Tumors and tumor-like conditions: Kaposi sarcoma. In: Rosai and Ackerman's Surgical Pathology. 10th Ed. China: Mosby Elsevier Inc. 2011; 187-189.

[9] Menkiti F.E, Ukah CO, Adelusola KA, Ezejiofor IF. Human herpesvirus-8 latent nuclear antigen-1 expression in Kaposi's sarcoma cases as seen in Nnewi, Anambra State: (A 10-year retrospective study). J Sci. Soc. 2020; 47: 153-7.

[10] Kyoung BL, Hye SL, Hee EL, So YP, Jin HC, Gheeyoung C, et al. Immunohistochemical Characteristics of Kaposi Sarcoma and its Mimicries. The Korean J Pathol. 2006; 40: 361-367.

[11] Moonim MT, Alarcon L, Freeman J, Mahadeva U, van der Walt JD, Lucas SB. Identifying HIV infection in diagnostic histopathology tissue samples-the role of HIV-1 p24 immunohistochemistry in identifying clinically unsuspected HIV infection: a 3-year analysis. Histopathology. 2010; 56(4): 530-541.

[12] Menkiti F.E, Ukah CO, Adelusola KA, Ezejiofor IF. The Usefulness of HIV-1p24 in Detecting the Presence of HIV Infection in Histopathology Tissue Specimens. Asian J Oncol. 2020; 7: 40-44. 
[13] Sung H, Ferlay J, Siegel RL, Laversanne M, Soerjomataram I, Jemal A, et al. Global Cancer Statistics 2020: GLOBOCAN Estimates of incidence and mortality worldwide for 36 Cancers in 185 countries. CA Cancer J Clin. 2021; 1-41.

[14] The International Agency for Research on cancer: WHO. The global cancer observatory: Nigeria fact sheets. GLOBOCAN 2020. March 2021.

[15] Mandong BM, Chirdan LB, Anyebe AO, Mannaseh AN. Histopathological study of Kaposi's sarcoma in Jos: a 16 year review. Ann Afr Med. 2004; 3: 174-6.

[16] Chalya PL, Mbunda F, Rambau PF, Jaka H, Masalu N, Mirambo M, et al. Kaposi Sarcoma: a 10-year experience with 248 patients at a single tertiary care hospital in Tanzania. BMC Res Notes. 2015; 8: 440.

[17] Kyalwazi SIC. Histological classification of Kaposi's sarcoma: a basis for chemotherapy. East Afr Med J. 1976; 53: 670-6.

[18] Akinde O, Obadofin O, Adeyemo T, Omoseebi O, Ikeri N, Okonkwo I, Afolayan O. Kaposi Sarcoma among HIV Infected Patients in Lagos University Teaching Hospital, Nigeria: A 14-Year Retrospective Clinicopathological Study. J. Skin Cancer. 2016.

[19] Yves-Marie R, Louis G, Jean-Jacques M, Jean-Michel C. Human Herpesvirus 8 Immunostaining, A Sensitive and Specific Method for Diagnosing Kaposi Sarcoma in Paraffin-Embedded Sections. Am J ClinPathol. 2004; 121: 330334.

[20] Mohammed AZ, Nwana EJC, Manasseh AN. Changing patterns of Kaposi sarcoma in Nigerians. Trop Doc. 2005; 35: 168-9.

[21] Mbah N, Abdbulkareem IH, Panti A. AIDS-associated Kaposi's sarcoma in Sokoto, Nigeria. Niger J Clin Pract. 2008; 11(3): 181-184.

[22] Ahmed A, Muktar HM. Epidemiology and treatment of Kaposi's sarcoma in HIV-1 infected individuals in a poor resource setting. In: Venketaraman V, editor. Global View of HIV Infection. Croatia: In Tech. 2011; 103-26.

[23] Eltom MA, Jemal A, Mbulaiteye SM, Devesa SS, Biggar RJ. Trends in Kaposi's sarcoma and non-Hodgkin's lymphoma incidence in the United States from 1973 through 1998. J Natl Cancer Inst. 2002; 94: 1204-10.

[24] National Agency for the Control of AIDS (NACA). Revised National HIV and AIDS strategic framework $2019-2021$. Abuja, Nigeria: 2019.

[25] Ochicha O, Edina ST, Muhammed AZ, Umar AB. Dermatological Malignancies in Kano, Northern Nigeria: A histopathological review. Ann. Med. Afr. 2004; 3: 188-191.

[26] Samaila MOA, Ayeni EI, Ahmed SA. Cancer Trend in Zaria: A 5year Hospital Based Analysis (2009-2013). The Zaria Cancer Registry Report. 2014.

[27] Nigeria Federal Ministry of Health. Technical Report on the 2003 National HIV/Syphilis Sentinel Survey among Pregnant Women attending Antenatal Clinics in Nigeria. Abuja, Nigeria: Federal Ministry of Health: April 2004.

[28] Zheng S. The growing threat of China's HIV epidemic. The lancet. 2018; 3 (7): e311 